\title{
Verbal Response Modes in Action:Microrelationships as the Building Blocks of Relationship Role Dimensions
}

\author{
Ayesha Shaikh",*, Lynne M. Knobloch-Fedders², William B. Stiles ${ }^{3}$ \\ ${ }^{1}$ Department of Psychology, Whittier College, Whittier, California 90608, United States \\ ${ }^{2}$ The Family Institute, Northwestern University, Evanston, Illinois 60201, United States \\ ${ }^{3}$ Department of Psychology, Miami University, Oxford, Ohio 45056, United States \\ *Corresponding Author: ashaikh@whittier.edu
}

Copyright (C) 2013 Horizon Research Publishing All rights reserved.

\begin{abstract}
Dimensions of interpersonal relationships, such as attentiveness, directiveness, and presumptuousness, have typically been assessed through impressionistic ratings or by aggregate scores derived from coding of specific (e.g., verbal) behaviors. However, the meanings of these dimensions rest on the interpersonal microrelationships that are actually observed by the raters or coders. In this qualitative study, the way these global relationship qualities were built from microrelationships at the utterance level was examined in passages from one medical interaction. Applications of microrelationships to future communications research are suggested.
\end{abstract}

Keywords Discourse Analysis; Physician-Patient Communication; Verbal Response Modes; Interpersonal Communication; Relationship Dimensions; Qualitative Analysis

\section{Introduction}

Each utterance of a verbal interaction may be considered a microrelationship - one unit of the verbal component of the relationship of a speaker to an other. Broader interpersonal dimensions such as dominance, deference, or affiliation are constructed from sequences of relational acts, including, though not restricted to, speech acts. Thus, understanding the microrelationships embodied in single utterances may illuminate the broader dimensions of relationships.

The Verbal Response Mode (VRM) coding system[1] is a general-purpose taxonomy of speech acts that classifies each utterance in verbal interactions (in the VRM system, an utterance is defined as a simple sentence; independent clause; nonrestrictive dependent clause; multiple predicate; or term of acknowledgment, evaluation, or address). In contrast to most other speech act coding systems, it is grounded in a theoretical formulation that specifies dimensions of interpersonal relationships. Its conceptual framework systematizes measurement and conceptual issues addressed in other microanalytic approaches such as conversational analysis, linking these with more molar psychological and psychotherapeutic theories[1,2]. Empirically, the VRM coding system has demonstrated applicability in a variety of contexts of interest to communication scholars (see [1], for a review), including professional service encounters such as medical interaction[3-6] and psychotherapy[7,8]; public discourse, such as Presidential speeches[9], labor-management negotiations[10], and radio call-in programs[11]; and a wide variety of ordinary conversations. These studies found systematic relations between verbal utterances and such interpersonal variables as attractiveness[12], gender differences[13], loneliness[14], and anxiety[15].

The present study aimed to elaborate the VRM understanding of the verbal aspect of relationships. Focusing intensively on one medical interview, we examined how the utterance-level microrelationships represented by the VRM codes combined to build the relational dimensions that characterized this patient-physician interaction. We chose a medical interview as the context because characteristic roles enacted by patients and physicians are relatively well known[16-19]. A qualitative examination of the process by which global relationship qualities (macrorelationships empirically defined by the dimensional scores) are built from microrelationships within the utterance-by-utterance interaction may contribute to understanding interpersonal problems more commonly identified at the macrorelationship level (e.g., physician dominance being linked to less patient satisfaction - see [20] for review).

We addressed our basic question - "how did this microrelationship build the macrorelationship?" - by determining how each utterance contributed to the global relational qualities of the interview. We wanted to find out whether the VRM role dimensions, defined in terms of combinations of speech act categories, are consistent with impressionistic descriptions of the physician-patient relationship derived from clinical experience and research[5,21,22].

\subsection{Verbal Response Modes as Microrelationships}


As a classification of speech acts the VRM taxonomy concerns what people $d o$ when they say something rather than the content of what they say[1]. It classifies each utterance in a conversation based on three dichotomous theoretical principles that describe the speaker's relationship to the other. The three theoretical principles are called source of experience (whether the topic is the speaker's experience or the other's experience), frame of reference (whether the experience is viewed from the speaker's subjective perspective or from a perspective shared with the other, and presumption (whether or not the speaker presumes to know what the other's experience is, was, will be, or should be). As shown in Table 1, these three forced choices (i.e., speaker vs. other on each principle) place every utterance into one of eight ( 2 X 2 X 2) mutually exclusive categories, or verbal response modes (VRMs). VRMs approximate categories familiar to interviewers: reflection, acknowledgment, interpretation, question, confirmation, edification, advisement, and disclosure. VRM categories are exhaustive in the sense that every comprehensible utterance can be coded (the designation uncodable is used only for utterances that are incomprehensible or inaudible on the recording).

VRM categories represent a taxonomy of microrelationships; theoretically, each combination of the principles describes a distinct way two people can interact.
For example, as Table 1 shows, a reflection is defined as the speaker expressing the other's experience using the other's frame of reference while presuming to know what the other's experience is. An acknowledgment is defined as a speaker expressing the other's experience using the other's frame of reference while not presuming to know what that experience is (hence, acknowledgements are empty of experiential content, e.g., "'mm-hm").

In VRM coding, each utterance is coded twice, once for its grammatical form and once for its pragmatic intent, using the same eight categories for each[1]. Form and intent definitions are shown in Table 1. An utterance that has the same form and intent is called a pure mode. For example, "I have pain when I move my legs" is a pure disclosure (first-person singular form revealing subjective experience), abbreviated DD (see Table 1 for the system of abbreviations). A mixed mode has the form of one mode and the intent of another. For example, "I went to the emergency room last week" has disclosure form (first-person singular) but edification intent (transmits objective information), abbreviated DE. The VRM system measures both the form and intent of each speech act because both of these levels (i.e., what is literally said and what is meant) are important contributors to an interpersonal relationship.

Table 1. Taxonomy of Verbal Response Modes

\begin{tabular}{|c|c|c|c|}
\hline $\begin{array}{ll}\text { Source } & \text { of } \\
\text { Experience } & \end{array}$ & $\begin{array}{l}\text { Frame of } \\
\text { Reference }\end{array}$ & \multicolumn{2}{|l|}{ Presumption } \\
\hline & & Other & Speaker \\
\hline \multirow[t]{3}{*}{ Other } & Other & REFLECTION (R) & ACKNOWLEDGMENT (K) \\
\hline & & $\begin{array}{l}\text { Form: Second person; verb implies internal experience } \\
\text { or volitional action. }\end{array}$ & $\begin{array}{l}\text { Form: Nonlexical or contentless utterances; terms of } \\
\text { address or salutation. }\end{array}$ \\
\hline & & $\begin{array}{l}\text { Intent: Puts other's experience into words; repetitions, } \\
\text { restatements, clarifications. }\end{array}$ & $\begin{array}{l}\text { Intent: Conveys receipt of or receptiveness to other's } \\
\text { communication; simple acceptance, salutations. }\end{array}$ \\
\hline \multirow[t]{3}{*}{ Other } & Speaker & INTERPRETATION (I) & QUESTION (Q) \\
\hline & & $\begin{array}{l}\text { Form: Second person ("you"); verb implies an attribute } \\
\text { or ability of the other; terms of evaluation. }\end{array}$ & $\begin{array}{l}\text { Form: Interrogative, with inverted subject-verb order or } \\
\text { interrogative words. }\end{array}$ \\
\hline & & $\begin{array}{l}\text { Intent: Explains or labels the other; judgments or } \\
\text { evaluations of other's experience or behavior. }\end{array}$ & Intent: Requests information or guidance. \\
\hline \multirow[t]{3}{*}{ Speaker } & Other & CONFIRMATION (C) & EDIFICATION (E) \\
\hline & & $\begin{array}{l}\text { Form: First person plural ("we") where referent } \\
\text { includes other. }\end{array}$ & Form: Declarative; third person (e.g., "he," "she," "it"). \\
\hline & & $\begin{array}{l}\text { Intent: Compares speaker's experience with other's; } \\
\text { agreement, disagreement, shared experience or belief. }\end{array}$ & Intent: States objective information. \\
\hline \multirow[t]{3}{*}{ Speaker } & Speaker & ADVISEMENT (A) & DISCLOSURE (D) \\
\hline & & $\begin{array}{l}\text { Form: Imperative, or second person with verb of } \\
\text { permission, prohibition, or obligation. }\end{array}$ & $\begin{array}{l}\text { Form: Declarative; first person singular ("I") or first } \\
\text { person plural ("we") where other is not a referent. }\end{array}$ \\
\hline & & $\begin{array}{l}\text { Intent: Attempts to guide behavior; suggestions, } \\
\text { commands, permission, prohibition. }\end{array}$ & $\begin{array}{l}\text { Intent: Reveals thoughts, feelings, wishes, perceptions, } \\
\text { or intentions. }\end{array}$ \\
\hline
\end{tabular}

Note: Both form and intent of each utterance are coded. Two-letter codes list form first, intent second. For example, "Would you close the window?" is question form with advisement intent (QA). 
Verbal Response Modes in Action:Microrelationships

as the Building Blocks of Relationship Role Dimensions

Table 2. Constituent Verbal Response Modes of Role Dimensions

\begin{tabular}{|c|c|c|}
\hline & Role Dimension & Constituent Verbal Response Modes \\
\hline 1 & Informativeness & Confirmation (C), Edification (E), Advisement (A), Disclosure (D) \\
\hline & Attentiveness & Reflection (R), Acknowledgment (K), Interpretation (I), Question (Q) \\
\hline 2 & Directiveness & Interpretation (I), Question (Q), Advisement (A), Disclosure (D) \\
\hline 3 & Acquiescence & Reflection (R), Acknowledgment (K), Confirmation (C), Edification (E) \\
\hline & Presumptuousness & Reflection (R), Interpretation (I), Confirmation (C), Advisement (A) \\
\hline
\end{tabular}

Note: Each role dimension index is the proportion of coded utterances (i.e., ignoring uncodable utterances) that were coded in the designated modes. These indices can be calculated separately for mode form and intent or averaged across form and intent. Role dimensions are arranged in 3 complementary pairs such that Attentiveness = 1 - Informativeness; Acquiescence = 1 - Directiveness; and Unassumingness = 1 - Presumptuousness.

\subsection{Role Dimensions: Combining Microrelationships into Relationship Qualities}

Role dimensions, an additional descriptive terminology, are empirically defined as the overall proportion of VRM utterances categorized by three bipolar classification principles. These classification principles are defined as the degree to which the speaker's relationship with the other is informative vs. attentive, directive vs. acquiescent, or presumptuous vs. unassuming[1]. For a passage of any length, indices of these role dimensions from each speaker toward the other can be calculated as the proportion of the speaker's coded utterances in the designated modes, as shown in Table 2. For example, informativeness is calculated as the proportion of utterances coded as advisement, disclosure, confirmation, or edification. Conversely, attentiveness is calculated as the proportion coded as interpretation, question, reflection, or acknowledgment - or, equivalently, as 1 minus informativeness (because every coded utterance is either attentive or informative; see Table 2). Thus, informativeness can be understood as the complement of attentiveness. Role dimension indices can be calculated separately for form and intent or averaged across form and intent.

The role dimensions (Table 2) are parallel to the principles of classification (Table 1). Both make the same distinctions, but they do so from two different perspectives. Whereas the principles take an utterance-level coder's perspective, indicating how to classify a particular utterance, the role dimensions take a passage-level observer's perspective, describing broader aspects of the interpersonal relationship[1,6,13]. The purpose of this parallel conceptualization is to quantitatively link the more impressionistic observer-level relational dimensions to reliably codeable utterance-level classification.

Attentiveness versus informativeness is based on the source of experience classification principle, which measures the degree to which a speaker's utterances concern the other's or the speaker's experience. Interpersonally, attentiveness has to do with manifest interest in the other, as well as attempts to ensure that the other's thoughts are expressed and considered in the conversation. Conversely, informativeness has to do with providing information to the other. Empirically, interviewers (e.g., doctors, psychotherapists, courtroom interrogators) are much more attentive than interviewees (e.g., patients, clients, witnesses; see [1] for a review).

Acquiescence versus directiveness is based on the frame of reference classification principle. Interpersonally, acquiescence has to do with acceding to the other's viewpoint, whereas directiveness measures the degree to which the speaker guides the conversation by using his or her own viewpoint. Empirically, non-directive therapists are much more acquiescent than directive therapists[7], and patients are more acquiescent than doctors[6].

Presumptuousness versus unassumingness is based on the presumption classification principle. Interpersonally, presumptuousness has to do with higher relative status, knowing the other, or assuming that one is important to the other, whereas unassumingness has to do with lower status and deference. Empirically, in mixed-status dyads (e.g., teacher-student, senior-freshman, psychotherapist-client, doctor-patient), the higher-status member is consistently more presumptuous than the lower-status member (see [1], for a review). Perhaps because of its link with relative status, conversations between social equals are marked by extremely close concordance in presumptuousness; that is, interactants seem to track each other's presumptuousness within very close tolerances [13].

\subsection{Measuring Relationship Dimensions with Verbal Response Modes}

The VRM coding system considers the form and the intent of each utterance as simultaneously representing one or the other pole on all three of the role dimensions (see Table 2). For example, in the case of pure modes, an edification, such as "The accident was on the ninth of September" (EE), is considered simultaneously informative, acquiescent, and unassuming. A question, such as "Was it a pretty bad car accident?" (QQ), is considered attentive, directive, and unassuming. An advisement, such as "Now turn this way" (AA), is considered informative, directive, and presumptuous. Mixed modes offer more subtle ways of representing microrelationships. For example, "Could you scoot forward a bit?" (QA) is directive in both form and 
intent, since both question and advisement are utterances made from the speaker's own frame of reference. However, this utterance is informative and presumptuous in intent (due to its advisement intent) but attentive and unassuming in form (due to its question form). The microrelationship represented in the mixed mode, "Could you scoot forward a bit?" (QA) is subtly more polite (attentive and unassuming) than its pure-mode counterpart, "Scoot forward a bit" (AA). As another example, consider the exchange (Dr: "Does that hurt?" [QQ] Pt: "Mm-hmm." [KD]), in which the patient's nonlexical acknowledgment form in effect uses the physician's words to convey her own private experience. In role dimension terms, this patient-to-physician microrelationship can be described as attentive and acquiescent in form, but informative and directive in intent.

Importantly, VRM coders do not impressionistically rate global qualities such as attentiveness or presumptuousness directly [1]. Instead, they decide whether each utterance is a disclosure, a question, or one of the other eight VRM categories. Thus, for example, to achieve a characteristic level of attentiveness, a physician must use precise proportions of attentive and informative utterances, one at a time, as the particular interview evolves. Thus, the coding system offers a systematic method of quantifying relationship constructs.

\subsection{Role Dimensions in Segments of Medical Interviews}

Researchers have described three typical segments of medical interviews: medical history; physical examination; and the conclusion, which includes diagnosis and treatment recommendations [18,22]. Aggregate characterizations based on utterance-by-utterance VRM coding[5] have confirmed a classic picture of interactional styles in medical interviews[16], and have demonstrated that patient and physician VRM role dimensions change systematically through these segments.

Previous VRM studies have demonstrated striking similarities in how these role dimensions are enacted across medical interview settings and even across countries[23]. In the medical history, patients are highly informative as they describe their problems. Physicians are attentive but also direct the conversation by inquiring about the history of the problem and other background data, using questions, which are both attentive and directive (see Table 2). This may prevent unnecessary storytelling but also may limit the full disclosure of patient concerns. Physicians' failures to facilitate patient disclosure at this point (e.g., by using acknowledgments, which are attentive but not directive; see Table 2) are associated with delayed problem presentation [18].

In the physical examination segment, the physician typically makes direct observations, performs tests, looks for signs, and elicits patient responses to diagnostic procedures[18]. The level of presumption necessary for the examination to take place is unusual for strangers and is usually acceptable only in intimate relationships. To compensate, physicians often employ high levels of attentiveness, and patients cooperate by assuming complementary positions of unassumingness and informativeness. In other words, physicians may balance the presumption that is in inherent in a physical exam by being socially polite. During this segment, the physician and patient must also listen attentively to each other - the patient to respond appropriately to the physician's instructions, and the physician to learn from the patient's reactions to the physical examination.

In the conclusion segment, the physician typically prescribes treatment; provides explanations; answers questions; and gives instructions for further tests, return visits, referrals, medication dosages, and so forth[18]. Thus, the physician's directiveness continues. The patient listens attentively to the physician, agrees to follow directions, and occasionally asks questions about the explanations or instructions (a directive posture).

The stability of patient and physician verbal roles within interview segments has some interesting implications for understanding microrelationships. For example, in the medical history segment physicians typically demonstrate attentiveness with $80 \%$ of their total utterances [23]. To do this (since no one utterance has an attentiveness "score" of $80 \%$ ) a physician has to use a rather precise mix of modes. Perhaps this reflects a social sense that roles must be kept in proper balance. It is as if, whenever some sort of subjective running average on a role dimension gets too high or too low (e.g., if physicians becomes too directive or too presumptuous), they use some other kind of utterance to bring their role back into balance. We looked for evidence of this sort of pattern in the passages we studied.

\subsection{Present Study}

In this study, we took a qualitative, microanalytic approach, seeking a detailed, fine-grained picture of the interaction, in order to understand the previously obtained stable aggregate profiles as they unfolded in the specific verbal acts of a particular interview. This approach was consistent with calls for context-sensitive, intensive analyses in real-world settings[24-26]. Such qualitative analysis requires thorough grounding - linking interpretations to specific observations, such as excerpts from transcripts, so readers can see and understand the basis for the interpretations[27-28].

To summarize, we sought to understand how microrelationships build role dimensions. By examining excerpts from a medical interview, showing in detail how patient and physician negotiated their respective roles, we aimed to contextualize quantitative findings of previous and future VRM research. We demonstrate a new method for studying the sequential development of interaction by examining microrelationships with the VRM system. Although we chose a medical interview for illustrative purposes, our goal was to show how understanding microrelationships could be useful to researchers interested in any form of dyadic, sequential interaction. 


\section{Method}

\subsection{Participants and Materials}

We selected one interview arbitrarily from a study of eight initial visits to a family practice clinic at an urban teaching medical center[5,29]. In this interview, a 19-year-old Caucasian woman presented with complaints that included dizziness, nosebleeds, and neck pain; she was interviewed by a 39-year-old Caucasian female medical resident. The participants consented to have their interviews used for research.

\subsection{Procedure}

As part of the earlier project[5], the entire 30-minute interview had been transcribed following VRM transcription requirements[1] and coded according to the VRM system. The coders (the first two authors) had been trained using a computer-based training program and coding manual (Stiles, 1992), and discussed their coding of practice transcripts with the third author before beginning work on the study. Working independently, the two coders agreed on the VRM form of $85 \%$ of the utterances and on the VRM intent of $81 \%$ of the utterances. Discrepancies between the two coders were discussed and resolved, yielding a final consensus code for each utterance[5].

For the present study, three passages were chosen from the selected interview, one from each segment (medical history, physical examination, and conclusion), on the basis that (a) they represented good examples of the interaction that characterized the respective segments and (b) they were reasonably comprehensible without reference to earlier or later material. Segments were easily distinguished by their content, which explicitly signaled the beginning and end of the physical examination segment. All three authors carefully re-examined and discussed the previously assigned VRM codes in the three selected passages and, by consensus, changed a few codes that appeared, upon reconsideration, to be inaccurate.

Lines of text in the transcript were numbered; the entire 30-minute interview was 538 lines long. The selected passages included about one-third of the entire interview: the medical history comprised lines 1-309 (of which our selected passage comprised lines 38-128), the physical examination comprised lines 310-384 (our selected passage comprised lines 314-352), and the conclusion comprised lines 384-538 (our selected passage comprised lines 494-538). Excerpted passages were located near the beginning of the history and examination segments and the end of the conclusion segment. The relative proportions of utterances spoken by patient and physician in each segment were consistent with previous research on medical interviewing [18].

With the VRM codes in hand, we read and re-read the transcript, considering how each utterance implemented and illustrated the patient's and physician's roles. We looked at each utterance with two lenses: we considered how each utterance contributed to the speaker's role in this interview segment, and we considered how it guided or constrained the other's role. Our qualitative analysis was conducted over an extended period of time as we explored and elaborated our understanding of the chosen passages.

\section{Results}

As characterized by VRM role dimensions within the excerpted passages (see Table 3), the physician-patient interaction was broadly similar to the typical relationship observed in all eight interviews in the parent project[5]. This was consistent with our intention to select characteristic passages within each interview.

Table 3. Role Dimension Proportions in Selected Passages and the Mean Proportions of 8 Interviews

\begin{tabular}{|c|c|c|c|c|c|c|}
\hline \multirow[t]{2}{*}{ Role Dimension } & \multicolumn{3}{|c|}{ Physician } & \multicolumn{3}{|c|}{ Patient } \\
\hline & $\begin{array}{l}\text { Medical } \\
\text { History }\end{array}$ & $\begin{array}{l}\text { Physical } \\
\text { Exam }\end{array}$ & Conclusion & $\begin{array}{l}\text { Medical } \\
\text { History }\end{array}$ & $\begin{array}{c}\text { Physical } \\
\text { Exam }\end{array}$ & Conclusion \\
\hline \multicolumn{7}{|l|}{ Selected Passage } \\
\hline Informativeness & 0.18 & 0.33 & 0.66 & 0.76 & 0.69 & 0.30 \\
\hline Attentiveness & 0.82 & 0.67 & 0.34 & 0.24 & 0.31 & 0.70 \\
\hline Directiveness & 0.52 & 0.68 & 0.53 & 0.21 & 0.42 & 0.35 \\
\hline Acquiescence & 0.48 & 0.32 & 0.47 & 0.79 & 0.58 & 0.65 \\
\hline Presumptuousness & 0.22 & 0.39 & 0.49 & 0.01 & 0.07 & 0.35 \\
\hline Unassumingness & 0.78 & 0.61 & 0.51 & 0.99 & 0.93 & 0.65 \\
\hline \multicolumn{7}{|l|}{ Eight-Interview Mean } \\
\hline Informativeness & 0.23 & 0.43 & 0.55 & 0.73 & 0.61 & 0.49 \\
\hline Attentiveness & 0.77 & 0.57 & 0.45 & 0.27 & 0.39 & 0.51 \\
\hline Directiveness & 0.54 & 0.68 & 0.62 & 0.33 & 0.37 & 0.35 \\
\hline Acquiescence & 0.46 & 0.32 & 0.38 & 0.67 & 0.63 & 0.65 \\
\hline Presumptuousness & 0.22 & 0.34 & 0.33 & 0.05 & 0.06 & 0.14 \\
\hline Unassumingness & 0.78 & 0.66 & 0.67 & 0.95 & 0.94 & 0.86 \\
\hline
\end{tabular}


Note: The 8 -interview means were based on the medical history, physical exam, and conclusion segments, respectively, in the 8 interviews reported by Shaikh et al.[5]. Role dimension proportions were calculated as the mean of form and intent values.

Next, we consider the microrelationships enacted in the entire texts of the three selected passages in order to illustrate how patient and physician roles unfolded. We ask readers to compare their developing global impression of this patient-physician relationship with the incremental modifications specified by the VRM coding. Close attention to microrelationships embodied in participants' speech acts shows how relationships are built- each question contributed to the physician's directiveness, attentiveness, and unassumingness; each acknowledgement furthered the patient's attentiveness, acquiescence, and unassumingness.

\subsection{Medical History Passage}

To gather information about the patient's history and background, physicians must attend to what patients report, but they must also be somewhat directive to expedite problem presentation. Physicians must also make some presumptions about the patients' experiences without alienating them. In other words, physicians need to balance the demands of what they must accomplish with a polite and caring style.

As Table 3 shows, the physician was relatively attentive and directive in the medical history segment, while the patient was complementarily informative and acquiescent. Additionally, as one might expect based on status differences, the physician was more presumptuous than the patient.

The physician's first utterance attentively acknowledged what had come before without encouraging further elaboration by using a form that was directive (interpretation; see Table 2), while the intent was acquiescent (acknowledgment). Whereas KK (pure acknowledgments such as " $\mathrm{mm}$-hm") tends to encourage elaboration, IK (evaluative words used to acknowledge, such as "okay" or "right") tends to truncate it[1]. Her second utterance shifted to being directive in intention (advisement), while maintaining an attentive form (interpretation). Finally, her third utterance seemed to have a subtle directive intent, though we decided this was "off record", that is, it hinted at a directive to go over the history but did not actually give this instruction[30].

$$
\begin{array}{lll}
\text { Dr. } & \text { OK. } & \text { IK } \\
& \text { Um, maybe you could tell me a little bit about why } \\
\text { you're here, } & \text { IA } \\
\text { and then we can um...go over your health history, } & \text { CC } \\
\text { health problems. } &
\end{array}
$$

The patient complied with the physician's directive by

\begin{tabular}{|c|c|c|}
\hline \multirow[t]{6}{*}{ Pt. } & $\begin{array}{l}\text { (Inaudible). I was in a car accident with, um, with } \\
\text { my boyfriend, }\end{array}$ & DE \\
\hline & and he didn't make it, & $\mathrm{EE}$ \\
\hline & so I'm, & $\begin{array}{l}\text { Not } \\
\text { coded }\end{array}$ \\
\hline & $\begin{array}{l}\text { I guess they were supposed to keep me (inaudible) } \\
\text { in the cars, }\end{array}$ & $\mathrm{DE}$ \\
\hline & but they didn't. I & $\mathrm{EE}$ \\
\hline & I & $\begin{array}{l}\text { Not } \\
\text { coded }\end{array}$ \\
\hline Dr. & First of - & $\begin{array}{l}\text { Not } \\
\text { coded }\end{array}$ \\
\hline Pt. & It was the ninth of September. & $\mathrm{EE}$ \\
\hline
\end{tabular}
offering personal and situational information (edification intent) describing her car accident. These informative, acquiescent, and unassuming utterances are complementary to the physician's role.

The patient's edifications presented background information, rather than her symptoms, and the physician sympathetically inquired further. In asking questions, the physician did not presume to know the patient's experience (unassuming) but showed interest (attentive).

$\begin{array}{lll}\text { Dr. } & \text { Was it a pretty bad car accident? } & \text { QQ } \\ \text { Pt. } & \text { Mm-hmm. } & \text { KE } \\ & \text { It was in [name of city]. } & \text { EE }\end{array}$

The QQ-KE sequence is a very common one in medical history segments (Stiles, 1996). The physician's closed question specifically constrained the patient to a narrow range of modes - and hence to particular values on the role dimensions. The patient's "mm-hm" was an acknowledgment form, but it was informative in intent (conveying the patient's experience), thus fulfilling a major purpose of history taking.

Next, the physician slightly shifted her role from purely directive to formally acquiescent by briefly reflecting the patient's interjections. This shift in roles was subtle - a mixed-mode question (RQ) - but served to temper her previous directiveness, perhaps in an effort to seek rapport early in the encounter.

$\begin{array}{lll}\text { Dr. } & \text { You were in [name of city]? } & \text { RQ } \\ \text { Pt. } & \text { Yeah. } & \text { KE } \\ \text { Dr. } & \text { And he died. } & \text { ER } \\ \text { Pt. } & \text { Mm-hmm. } & \text { KE }\end{array}$

The physician immediately reassumed a directive role by asking a pure-mode question (QQ), guiding the patient into another QQ-KE sequence. This is an example of the physician interrupting the patient's illness narrative[31], which is common in medical encounters where physicians must balance competing demands for caring attentiveness against the need to gather relevant information efficiently.
Dr. Was there anyone else in the car?
QQ
Pt. No,
$\mathrm{KE}$
it was just me and him.
$\mathrm{EE}$ 
The physician's next pure acknowledgement seemed to encourage the patient to continue her personal disclosures.

$\begin{array}{lll}\text { Dr. } & \text { Ah hah, } & \text { KK } \\ \text { Pt. } & \text { And, why I'm here is because they want, } & \text { ED } \\ & \text { my momma says my head, } & \text { EE } \\ & \text { I've been having nosebleeds the last three days. } & \text { DE } \\ & \text { And I've been getting dizzy spells, } & \text { DD } \\ & \text { and the back of my neck hurts } & \text { ED } \\ \text { Dr. } & \text { (inaudible) } & \text { UU } \\ \text { Pt. } & \text { ever since the car wreck. } & \text { continuation }\end{array}$

As after the previous QQ-KE sequence, the physician used RQ. The reflection form was acquiescent - responsive to the patient's focus on subjective, personal experience (pain, dizziness) - but the question intent reasserted the physician's directiveness, effectively controlling what happened next. The patient responded in a complementary way $(\mathrm{KD})$, and the physician followed up with a pure question. With these questions, the physician limited the patient's personal disclosures, directing the conversation to observable facts; that is, the question content called for edification intents rather than exploring the patient's personal distress.

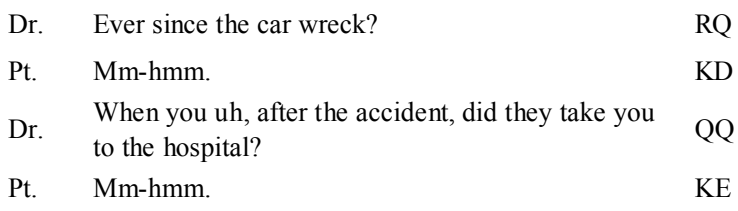

After the next question-edification sequence, the physician responded by providing a bit of explanation (edification). We speculate that this served to balance the physician's role, to prevent it from becoming too directive and attentive.

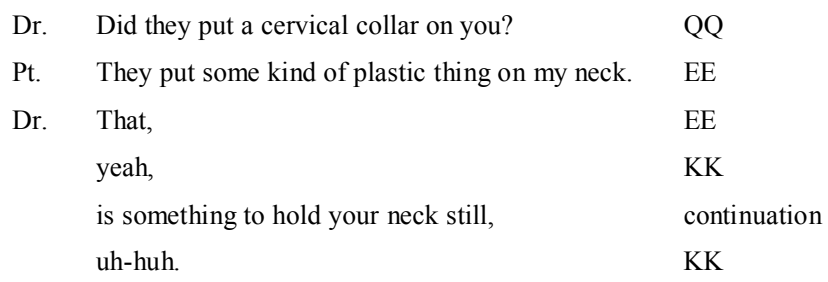

A similar sequence followed, this time marked by the physician disclosing her underlying intentions in pursuing the issue.

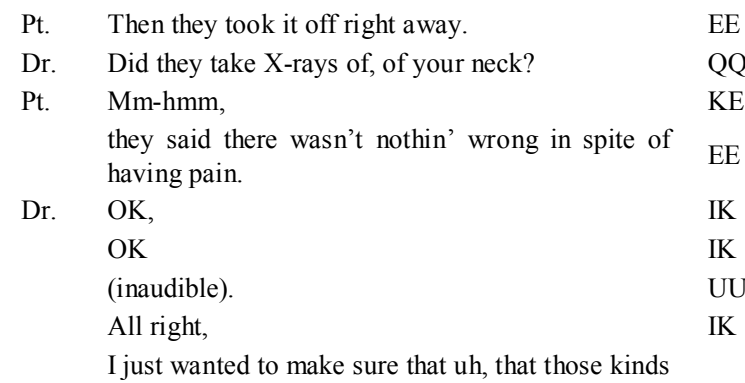

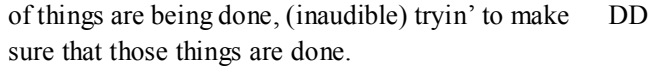

These informative physician utterances may have freed her to pursue (attentive, directive) questioning, which called for patient (informative) disclosures and edifications.

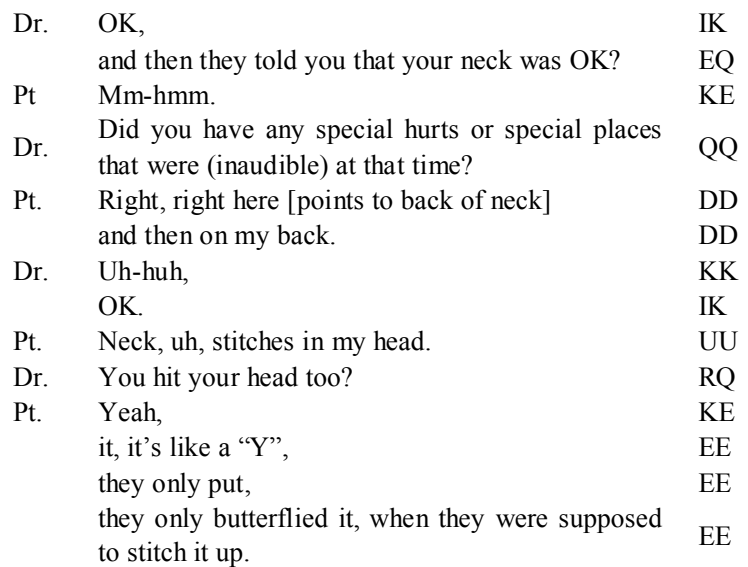

The physician's questions tended to constrain the patient's informative responses to be objective (edification, i.e., shared frame of reference, technically acquiescent) rather than subjective (disclosure, i.e., personal frame of reference, technically directive).

Poor quality of the recording made a few utterances uncodable (UU) in the next sequence, though apparently these were understandable to the participants.

$\begin{array}{lll}\text { Dr. } & \begin{array}{l}\text { Did they uh, um...uh (inaudible) and that type of } \\ \text { stuff? }\end{array} & \text { QQ } \\ \text { Pt. } & \text { Mm-hmm. } & \text { KE } \\ \text { Dr. } & \text { Yeah, } & \text { KK } \\ & \text { uh-huh, } & \text { KK } \\ & \text { yeah, } & \text { KK } \\ & \text { as I say, did they (inaudible)? } & \text { QQ } \\ \text { Pt. } & \text { Mm-hmm. } & \text { KU } \\ \text { Dr. } & \text { Did they (inaudible) wake you up during the night, } & \text { QQ } \\ & \text { and make sure that you were waking up, and that kind } & \text { QQ } \\ & \text { of thing? } & \text { KE } \\ \text { Pt. } & \text { Yeah } & \text { UE } \\ & \text { (inaudible) got home at three-thirty in the morning. } & \text { (inaudible) } \\ \text { Dr. } & \text { Uh-huh. } & \text { KK } \\ \text { Pt. } & \text { So when I was in (inaudible). } & \text { UU } \\ \text { Dr. } & \text { Uh-huh. } & \text { KK } \\ & \text { (inaudible). } & \text { UU } \\ & \text { Oh, } & \text { KK } \\ & \text { uh-huh, } & \text { KK } \\ & \text { OK, } & \text { IK } \\ & \text { good. } & \text { Before then, how was your health? } \\ & \text { Pretty good. } & \text { QQ } \\ & & \end{array}$


When the patient responded that her health was "pretty good," the physician used reflection intents while checking an earlier problem with her tonsils. This brief presumptuousness stood out against the history segment's generally unassuming exchanges.

$\begin{array}{ccc}\text { Dr. } & \begin{array}{c}\text { I know you had some problems with your tonsils } \\ \text { which they yanked out a couple of years ago. }\end{array} & \text { DR } \\ \text { Pt. } & \text { Mm-hmm. } & \text { KE } \\ \text { Dr. } & \text { It's the same thing, } & \text { ER } \\ & \text { OK. } & \text { IK } \\ \text { Pt. } & \text { Mm-hmm. } & \text { KC } \\ \text { Dr. } & \text { That's good. } & \text { EI }\end{array}$

After checking, the physician returned to questions and acknowledgements, implementing the characteristic attentive and unassuming yet directive physician role during history taking.

$\begin{array}{lll}\text { Dr. } & \begin{array}{l}\text { Um where, (inaudible) } \\ \text { ask you some other questions about your nose }\end{array} & \text { UU } \\ & \text { bleeding. } & \text { QQ } \\ \text { Dr. } & \text { Did you ever bleed before the (inaudible)? } & \text { UU } \\ \text { Pt. } & \text { [patient shakes head no] (inaudible) } & \text { QQ } \\ \text { Dr. } & \text { Have you ever been stuffy, } & \text { QQ } \\ & \text { or had a stuffy nose? } & \text { KE } \\ \text { Pt. } \quad \text { Mm-hmm, } & \text { DE } \\ & \text { like right now. } & \text { RQ } \\ \text { Dr. You have a stuffy nose right now? } & \text { KE } \\ \text { Pt. } \quad \text { Mm-hmm. } & \end{array}$

After several such exchanges, the physician inserted another brief informative episode, using disclosures and edifications to explain her questions. Interestingly, nothing in the patient's verbal behavior suggested she was seeking additional information or clarification (e.g., the physician's informativeness was not a response to the patient asking questions). Instead, we speculated, the physician seemed to sense that some information giving was interpersonally necessary to balance her questioning.

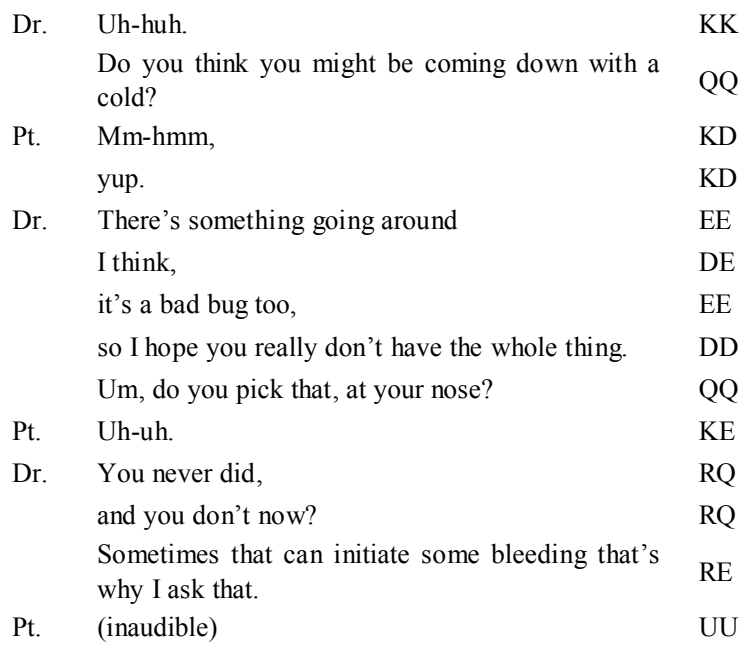

Following this brief physician informativeness, the primary question-and-answer pattern continued (directive-attentive physician, acquiescent-informative patient). Note that in the next exchange, the patient was subtly more directive through her use of disclosures, saying she didn't know or couldn't remember, rather than acquiescing by actually answering the questions.

$\begin{array}{lll}\text { Dr. } & \text { How did you stop it? } & \text { QQ } \\ \text { Pt. } & \begin{array}{l}\text { By getting a wet washcloth and putting it on the back of } \\ \text { my neck, and holding my neck back and lying down. }\end{array} & \text { DE } \\ \text { Dr. } & \text { Uh-huh, } & \text { KK } \\ & \text { how long did it take to stop? } & \text { QQ } \\ \text { Pt. } & \text { Oh, } & \text { KK } \\ & \text { maybe four or five minutes, } & \text { EE } \\ & \text { I don't remember. } & \text { DD } \\ \text { Dr. } & \text { What made it start? } & \text { QQ } \\ \text { Pt. } & \text { I don't know. } & \text { DD } \\ \text { Dr. } & \text { Heat, } & \text { QQ } \\ & \text { or did you bend down? } & \text { QQ } \\ \text { Pt. } & \text { Oh, } & \text { KK } \\ & \text { I blew my nose! } & \text { DE }\end{array}$

At the end of the selected passage, for the second time within the excerpt, the physician inserted a presumptuous sequence, reflecting what the patient had conveyed. As part of this sequence the physician used IK and a simple evaluative interpretation (EI), serving to truncate the exchange about the nosebleed.

$\begin{array}{ll}\text { Dr. You blew your nose, } & \text { RR } \\ \text { OK, } & \text { IK } \\ \text { and it started bleeding, } & \text { ER } \\ \text { OK, } & \text { IK } \\ \text { that's fine. } & \text { EI }\end{array}$

\subsection{Physical Examination Passage}

The relatively high levels of presumptuousness and directiveness required to perform a physical examination verbal as well as physical - demand clear markers of when it begins and ends. It also requires culturally sanctioned acceptance of such behavior by the patient. Presumably its social impact is buffered by the concomitant attentive focus on the patients' experiences. Patients typically focus on their own experiences (see Table 3). The selected passage, essentially the start of the examination, began with the physician's unassuming utterances whose content signaled the transition. Her first presumptuous advisement intent was softened by its unassuming question form.

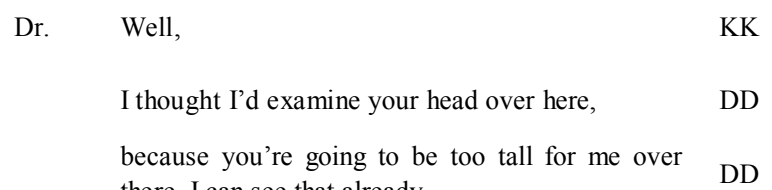

because you're going to be too tall for me over there, I can see that already. $\mathrm{DD}$ 
D

$$
\begin{aligned}
& \text { All right, } \\
& \text { can you bend your neck this way? }
\end{aligned}
$$

IK

QA

The patient responded in complementary informative ways. Although the physician maintained her attentive directiveness, the reflection intent of the repetition added to the presumptuousness.

$\begin{array}{lll}\text { Pt. } & \text { That hurts right there. } & \text { ED } \\ \text { Dr. } & \text { That hurts right here. } & \text { ER } \\ \text { Pt. } & \text { Mm-hmm. } & \text { KC } \\ \text { Dr. } & \text { OK, } & \text { IK } \\ & \text { does it hurt anywhere else if I push? } & \text { QQ } \\ \text { Pt. } & \text { It hurts right here. } & \text { ED }\end{array}$

When the patient indicated she experienced some pain, the physician checked (KQ) and quickly offered an apology (DD), which served to briefly reveal her own internal state. The patient's ED response was formally acquiescent but technically directive in intent, understandable as subtly influencing the exam's course (i.e., conveying what would be painful).

$\begin{array}{cll}\text { Dr. } & \text { Hm? } & \text { KQ } \\ & \text { I'm sorry. } & \text { DD } \\ \text { Pt. } & \text { Over here. } & \text { ED }\end{array}$

The physician deferred by becoming complementarily acquiescent, using acknowledgments and mixed-mode reflections.

$\begin{array}{lll}\text { Dr. } & \text { Oh, } & \text { KK } \\ & \text { it hurts over here. } & \text { ER } \\ & \text { But it also hurts at this spot, } & \text { ER } \\ & \text { Tenderness } & \text { ER } \\ \text { Pt. } & \text { Mm-hmm } & \text { KC } \\ \text { Dr. } & \text { when I press right here. } & \text { continuation }\end{array}$

The physician resumed her directive role by using a string of pure-mode questions. However, she punctuated those questions with acknowledgments, which seemed to balance the relational impact of the physician's directiveness with attentive acquiescence.

$\begin{array}{cll}\text { Dr. } & \text { All right, } & \text { IK } \\ & \text { here? } & \text { QQ } \\ \text { Pt. } & \text { Mm-hmm. } & \text { KD } \\ \text { Dr. } & \text { OK, } & \text { IK } \\ & \text { here. } & \text { QQ } \\ \text { Pt. } & \text { Mm-hmm. } & \text { KD } \\ \text { Dr. } & \text { OK, } & \text { IK } \\ & \text { up here? } & \text { QQ }\end{array}$

Pt. Mm-hmm.

KD

Next, the physician added advisements to her question-and-acknowledge pattern, which increased her directiveness and presumptuousness. Technically, she imposed examination procedures on the patient, while the patient remained compliantly unassuming by responding (partly nonverbally) and answering the questions.

$\begin{array}{cll}\text { Dr. } & \text { OK, } & \text { IK } \\ & \text { now turn this way, } & \text { AA } \\ & \text { does that hurt? } & \text { QQ } \\ \text { Pt. } & \text { Mm-hmm. } & \text { KD } \\ \text { Dr. } & \text { No? } & \text { QQ } \\ & \text { Turn this way, } & \text { AA } \\ & \text { does that hurt? } & \text { QQ } \\ \text { Pt. } & \text { Mm-hmm. } & \text { KD }\end{array}$

Again, the physician responded to the patient's report of pain with an empathic reflection (ER - attentive, acquiescent, but presumptuous in intent), and by interspersing truncating acknowledgements (IK). The patient's mixed modes with disclosure intent (ED, KD) were formally acquiescent but intentionally directive, which asserted her own subjective frame of reference.

$\begin{array}{lll}\text { Dr. } & \begin{array}{l}\text { That hurts, } \\ \text { now where does that hurt, that now the big }\end{array} & \text { QR } \\ & \text { hurt, } & \text { QQ } \\ \text { Dr. } & \text { where does that hurt? } & \text { ED } \\ \text { Pt. } & \text { Right there. } & \text { IK } \\ \text { Dr. } & \text { Right } & \text { ED } \\ \text { Pt. } & \text { Hurts right here. } & \text { RQ } \\ \text { Dr. } & \text { Right here? } & \text { KD } \\ \text { Pt. } & \text { Mm-hmm. } & \text { IK } \\ \text { Dr. } & \text { OK. } & \text { UU } \\ \text { Pt. } & \text { (inaudible). } & \end{array}$

In the following sequence, the physician used a question form to temper the presumptuousness of her advisement intent (QA). During her examination of the patient's back, she used IK responses, seemingly to signal that each physical probe had been completed. The patient's compliance was largely nonverbal. The physician's two disclosures gave information about her intentions.

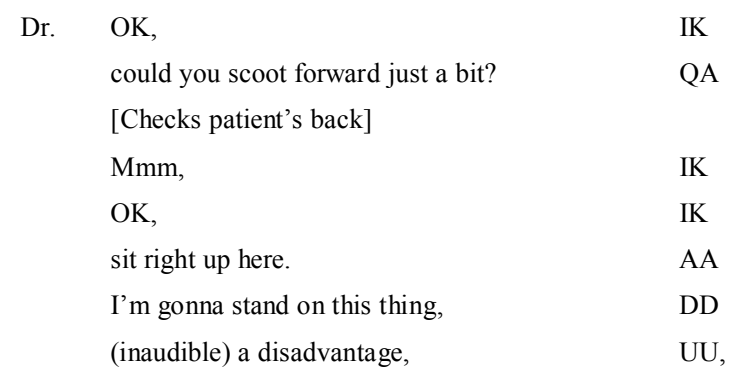




$\begin{array}{lll} & \text { but we work with it. } & \text { DD } \\ & \text { OK, } & \text { IK } \\ & \text { (inaudible) up and down. } & \text { UU } \\ & \text { Say ahhh. } & \text { AA } \\ & \text { Stick your tongue out } & \text { AA } \\ & \text { and say ahh. } & \text { AA } \\ \text { Pt. } & \text { Ahhh. } & \text { IK } \\ \text { Dr. } & \text { Good. } & \text { II } \\ & \text { OK. } & \text { IK }\end{array}$

\subsection{Conclusion Passage}

In the conclusion segment, physicians must efficiently communicate a great deal of information to patients in a way that promotes patients' compliance. To produce the role dimension proportions shown in Table 3, this physician followed the typical pattern of shifting to much greater informativeness as she described the results of the examination. In response, the patient was much more attentive, listening to and acknowledging diagnostic information and medical instructions. The physician was still directive and presumptuous as she specified what the patient's behavior and experience should be. As is typical, the physician talked more than the patient.

At the beginning of our selected passage, the physician proposed that the patient have an X-ray done on her neck. Although this hinted at a directive (off-record advisement; see [30]), her utterances were technically unassuming disclosing and describing a plan. This softer phrasing may have reflected the physician's attempt to get the patient to comply. (See [1], p. 116, for a technical discussion of coding evaluative words such as the "okays" at the end of this section.)

$\begin{array}{lll}\text { Dr. Well, } & \text { KK } \\ & \text { what I want to do is send you over to radiology, } & \text { ED } \\ & \text { and they're going to X-ray your neck } & \text { EE } \\ & \begin{array}{ll}\text { and just make sure that there isn't in fact, there's } \\ \text { nothing structurally wrong in there, }\end{array} & \text { EE } \\ \text { OK? } & \text { QQ } \\ \text { Pt. } & \text { OK. }\end{array}$

When the patient agreed, the physician prescribed exercises to alleviate her neck pain (informative and directive). These prescriptions were delivered using mixed modes - microrelationships that softened the directive presumptuousness of the advisement intents.

\footnotetext{
Um, the other advice we'll give you is, um, to

Dr. exercise your neck slowly, not to the point of EA

pain.

But flexion, extension, rotation to right, rotation to left, five times, twice a day.

Not to the point of pain now

$\begin{array}{lll} & \text { right. } & \text { IA } \\ \text { Pt. } & \text { Right. } & \text { IC } \\ \text { Dr. } & \text { So you go, one, two. } & \text { AA } \\ \text { Pt. } & \text { OK. } & \text { IC }\end{array}$

After providing these instructions, the physician again elicited the patient's agreement with her instructions (confirmation) by adding a tag question. The relational effect of providing the question and subsequent rationale for the advice she gave further attenuated the presumptuousness of her advisements.

$\begin{array}{lll}\text { Dr. } & \begin{array}{l}\text { OK, } \\ \text { and you do that in all those directions, }\end{array} & \text { IK } \\ & \text { OK? } & \text { AA } \\ & \begin{array}{l}\text { That, you've got a lot of muscle tension back } \\ \text { there, }\end{array} & \text { RE } \\ \text { Dr. } \quad \begin{array}{l}\text { and uh that oughta help a little bit. } \\ \text { Dr. } \quad \begin{array}{l}\text { Sometimes uh another way to help is, relaxation } \\ \text { method. }\end{array}\end{array} & \text { EI } \\ & \text { EE } \\ \text { Dr. } \quad \begin{array}{l}\text { hrequently if you're lying down it's a little bit } \\ \text { helpful comfortable just to roll the neck. }\end{array} & \text { EA }\end{array}$

The patient next appeared to shift to an informative position by referring to a lawsuit, presumably related to the neck injury she suffered in the car accident. Unfortunately, these utterances were mostly inaudible and uncodable. In any case, this bid for a new topic was unsuccessful; the physician disregarded the patient's interjection, and instead resumed providing instructions about neck relaxation.

\begin{tabular}{|c|c|c|}
\hline Pt. & $\begin{array}{l}\text { (Inaudible) managing this lawsuit, } \\
\text { it's been going on. }\end{array}$ & $\begin{array}{l}\text { UU } \\
\text { EU }\end{array}$ \\
\hline Dr. & And & $\begin{array}{l}\text { Not } \\
\text { coded }\end{array}$ \\
\hline Pt. & (inaudible) & UU \\
\hline Dr. & $\begin{array}{l}\text { And when you're lying down, you just want to } \\
\text { start thinking, "My legs are heavy and warm, } \\
\text { my arms are heavy and warm. It's good that my } \\
\text { breathing is quiet. My heart is regular, my } \\
\text { forehead is cool, my neck is relaxed." }\end{array}$ & $\begin{array}{l}\quad \text { RA } \\
\text { (quoted } \\
\text { material } \\
\text { treated } \\
\text { part } \\
\text { utterance) }\end{array}$ \\
\hline Pt. & [Laughter]. & $\begin{array}{l}\text { Not } \\
\text { coded }\end{array}$ \\
\hline \multirow[t]{5}{*}{ Dr. } & It's not easy, at first, & EI \\
\hline & but it gets easier & EA \\
\hline & $\begin{array}{l}\text { and that will be a good way for you to relax if } \\
\text { you feel yourself tensing up in there. }\end{array}$ & EA \\
\hline & Yeah, & KK \\
\hline & you can make yourself feel real good that wa & II \\
\hline
\end{tabular}

Echoing an earlier-noted stratagem, the physician used unassuming disclosures and edifications to convey off-record directives - describing her intention to prescribe medications without (presumptuously) ordering the patient to take them. The patient's pure acknowledgments conveyed receipt but did not formally agree to comply with the regimen.

Dr. I want to give you some Motrin, DD

(inaudible) anti-inflammant, uh, which is the EE 


\begin{tabular}{lll}
\multicolumn{3}{l}{ pill part. } \\
& Remember we thought it wouldn't be pills, & RR \\
Pt. & Mmmm. & KK \\
Dr. & it might be a lot of things. & EE \\
& So um, the pill will be a Motrin, & EE \\
Pt. & Mmmm & KK
\end{tabular}

When the physician summarized with a pure advisement, the patient's "mm-hm" again merely acknowledged the information rather than agreeing to comply with the directive (which would have been coded IC).

$\begin{array}{lll}\text { Dr. } & \begin{array}{l}\text { and you'll take one tablet for, um, three times a } \\ \text { day. }\end{array} & \text { AA } \\ & \begin{array}{l}\text { And, um, and then the other part is, I'm going } \\ \text { to give you a request, a referral form to take to }\end{array} & \text { DD } \\ \text { the therapist. } & \text { KK }\end{array}$

Winding up the interview, the physician made four consecutive pure-mode advisements (directive, presumptuous). The patient again merely acknowledged the instructions (unassuming and acquiescent, but attentive rather than informative about her own intentions). The physician might have elicited greater evidence of patient commitment if she had asked questions rather than using advisements.

\begin{tabular}{|c|c|}
\hline \multirow[t]{4}{*}{ Dr. } & $\begin{array}{l}\text { Check with your insurance company, if they're } \\
\text { going to pick up the bill, }\end{array}$ \\
\hline & make an appointment \\
\hline & and follow through with the form. \\
\hline & $\begin{array}{l}\text { If they're not, you'll have to decide for yourself } \\
\text { whether or } \\
\text { not you want to pay for it. }\end{array}$ \\
\hline Pt. & Hmm. \\
\hline
\end{tabular}

Interestingly, as the interview ended, the patient finally asked what might have been a question. Although it was inaudible and uncodable, we hypothesized it may have been a question about the recording of the interview for research. However, the physician did not know the answer, and the interview ended.

$\begin{array}{lll}\text { Dr. } & \text { OK, } & \text { IK } \\ & \text { so let me get, go out and take care of those things. } & \text { AD } \\ & \text { Stay right here, } & \text { AA } \\ \text { Pt. } & \text { (inaudible) stop taping. } & \text { UU } \\ \text { Dr. } & \text { I have no idea actually. [End of interview]. } & \text { DU }\end{array}$

\section{Discussion}

VRM research has most often been used to provide global, quantitative assessments of communication, but as our analysis reveals, it also has the capacity to provide qualitative microlevel analysis of interactions. Examining microrelationships with the VRM system offers a way for communication scholars to study the sequential development of interaction. It also constitutes a practical way to bridge the gap between quantitative and qualitative research methodologies.

Our analysis of microrelationships in this medical interview revealed that the participants' sequencing of modes seemed to reflect their attempts to balance each segment's task demands with interpersonal demands. For example, in the selected medical history passage, the physician balanced her information seeking by periodically inserting explanations, and she tempered her presumptuous advisements by phrasing them in unassuming forms or interspersing them with reflections or questions that checked on the patient's interpersonal condition. That is, she seemed to shift her position systematically as she attempted to balance history-taking - attentively focusing on patient data and directively keeping the conversation on topic - with (brief) indications of interpersonal sensitivity and care by occasionally offering reasons for her line of inquiry (edifications) or disclosing her intentions. Interestingly, the patient showed little shifting in her role. Her personal disclosures at the beginning and end of the segment were met by (directive) questions that returned the conversation to the physician's idea of the proper topic. For the most part, the patient remained acquiescent throughout the whole interview.

As the interview proceeded and her tasks changed, the physician's position shifted along the attentive-informative dimension. She was highly attentive in the medical history (gathering information), relatively balanced in the examination (instructing the patient in the procedures but attending to the responses), and informative in the conclusion (prescribing and explaining). Yet within each segment, there was some interplay (explaining in the history; acknowledging pain in the examination; listening in the conclusion), perhaps to lubricate a relationship that needed some human connection or cordiality to succeed at the medical task of diagnosis and treatment.

The presumptuousness necessary for conducting the physical exam and the conclusion segments seemed to prompt the physician to attenuate it at times. For example, she softened the impact of her presumptuous intents by using unassuming forms (e.g., QA, ER). Her efforts at attenuating presumptuousness seemed spread across each segment, as if the physician was seeking to keep the interaction from getting out of balance. For example, perhaps to encourage patient compliance with her prescriptions in the conclusion segment, the physician balanced the presumptuousness and directiveness of her advisements by asking "tag" questions and providing edifications and disclosures (primarily as explanations for her instructions). Social norms typically allow close concordance of presumptuousness among social equals[13]. Although physicians are allowed great latitude, 
they must acknowledge patients' standing to some degree. Toward the end of the interaction, the physician (perhaps feeling that she had presumed too much) briefly shifted from advice giving to disclosures. Interestingly in this regard, the patient did not confirm that the physician's instructions would be followed.

This patient (like patients in medical interviews generally) exhibited high levels of acquiescence and unassumingness, and examination of the microrelationships indicated some of the processes by which this position was maintained. The patient's early attempts to disclose personal information in the medical history was countered by the physician's immediate directive to focus on the facts. This pattern is consistent with observations by other researchers that physicians tend to discourage patient attempts to discuss personal and social issues by interrupting, de-emphasizing, or changing the topic [e.g., 32-34], contrary to suggestions that humane and effective care depends on strengthening the patient's voice[16].

Studying microrelationships may contribute to understanding interpersonal problems more commonly identified at the macrorelationship level. For example, in medical interviewing, physician dominance (i.e., presumptuousness and directiveness) is linked to reduced patient satisfaction (see review by Kiesler \& Auerbach[20]), a greater likelihood of malpractice claims[35] and lower treatment compliance, which usually results in poorer treatment outcomes (see [18] for review). Although less patient participation in medical interviews is associated with poorer outcome, patient participation in medical interviews can be increased by both physician and patient interventions[19,36].

We suggest that an understanding of how microrelationships build macrorelationships could enable speakers to negotiate a balance for their desired goals. For example, physicians could adjust their utterances to strike the appropriate balance between getting the patient to disclose enough information while still keeping the interview focused. Similarly conflicting pressures, with similar demands for balance, undoubtedly exist in other communication contexts such as intimate interpersonal relationships, impression management by politicians, and classroom teaching (e.g., conveying difficult information versus maintaining strong rapport). The efforts at balance may need to be appropriately timed to be effective, though we cannot specify what external or internal cues might determine interactants' choice of which form and intent to use.

\section{Conclusion}

This analytic approach offers a strategy for understanding how verbal behavior at the utterance level contributes to the larger context of interaction in a multitude of other relational contexts beyond medical interviewing. Analyses of this type can investigate ways to improve communication in relationships, and future research could be used to address specific questions in this regard. For example, is patient passivity spontaneous, or is it prompted or maintained by physician behavior? How do speech acts impact relationship satisfaction? How do writers represent relationships in various media? Microrelationships derived from VRM coding can objectively describe the patterns in communication observed in any such context. The VRM system thus offers both a theoretical framework and an empirically validated way to quantitatively describe how verbal behavior at the microlevel impacts the macrolevel of relationships. We suggest that the depth offered by this link adds both flexibility and objectivity to the study of relational aspects of interpersonal communication.

Endnote Transcription of the medical interview used in this analysis included standard orthography and punctuation, with careful attention to including non-lexical acknowledgments (e.g., $\mathrm{mm}-\mathrm{hm}$ ).

\section{REFERENCES}

[1]. W. B. Stiles. Describing Talk: A Taxonomy of Verbal Response Modes, Sage, Newbury Park, CA., 1992.

[2]. W. B. Stiles. Foreword: Filling the Gaps. In A. Peräkylä, C. Antaki, S. Vehviläinen, \& I. Leudar (Eds.), Conversation Analysis and Psychotherapy, Cambridge University Press, $1-4,2008$

[3]. J. D. Cape, W. B. Stiles. Verbal exchange structure of general practice consultations with patients presenting psychological problems, Journal of Health Psychology, 3, 5-21, 1998 .

[4]. L. Meeuwesen, C. Schaap, C. van der Staak. Verbal analysis of physician-patient communication, Social Science \& Medicine, 32, 1143-1150, 1991.

[5]. A. Shaikh, L. M. Knobloch, W. B. Stiles. The use of a verbal response mode coding system in determining patient and physician roles in medical interviews, Health Communication, 13(1), 49-60, 2001.

[6]. W. B. Stiles, S. M. Putnam, S. A. James, M. D. Wolf. Dimensions of patient and physician roles in medical screening interviews, Social Science \& Medicine, 13A, 335-341, 1979.

[7]. W. B. Stiles. Verbal response modes and psychotherapeutic technique, Psychiatry, 42, 49-62, 1979.

[8]. W. B. Stiles, D. A. Shapiro. Verbal exchange structure of brief psychodynamic-interpersonal and cognitive-behavioral psychotherapy, Journal of Consulting and Clinical Psychology, 63, 15-27, 1995.

[9]. N. L. Miller, W. B. Stiles. Verbal familiarity in American presidential nomination acceptance speeches and inaugural addresses (1920 1981), Social Psychology Quarterly, 49, 72 81, 1986.

[10]. S. Hinkle, W. B. Stiles, L. A. Taylor. Verbal processes in a labour/management negotiation, Journal of Language and 
Social Psychology, 7, 123 136, 1988.

[11]. W. H. Henricks, W. B. Stiles. Verbal processes on psychological radio call in programs: Comparison with other help intended interactions, Professional Psychology: Research and Practice, 20, 315 321, 1989.

[12]. W. B. Stiles, N. C. Walz, M. A. B. Schroeder, L. L. Williams, W. Ickes. Attractiveness and disclosure in initial encounters of mixed-sex dyads, Journal of Social and Personal Relations, 13, 305-314, 1996.

[13]. W. B. Stiles, L. M. Lyall, D. P. Knight, W. Ickes, M. Waung, C. L. Hall, B. E. Primeau. Gender differences in verbal presumptuousness and attentiveness, Personality and Social Psychology Bulletin, 23, 759-772, 1997.

[14]. W. W. Sloan, C. H. Solano. The conversational styles of lonely males with strangers and roommates, Personality and Social Psychology Bulletin, 10, 293-301, 1984.

[15]. W. B. Stiles, P. L. Shuster, J. A. Harrigan. Disclosure and anxiety: A test of the fever model, Journal of Personality and Social Psychology, 63, 980-988, 1992.

[16]. E. G. Mishler. The Discourse of Medicine, Albex Publishing Corporation, Norwood, NJ, 1984.

[17]. A. Peräkylä. Conversation analysis: A new model of research in doctor-patient communication, Journal of the Royal Society of Medicine, 90, 205-208, 1997.

[18]. D. L. Roter, J. A. Hall. Doctors Talking with Patients/Patients Talking with Doctors: Improving Communication in Medical Visits, Praeger Publishers, Westport, CT, 2006.

[19]. R. L. Street. Information-giving in medical consultations: The influence of patients' communicative styles and personal characteristics, Social Science Medicine, 32, 541-548, 1991.

[20]. D. J. Kiesler, S. M. Auerbach. Integrating measurement of control and affiliation in studies of physician-patient interaction: The interpersonal circumplex, Social Science \& Medicine, 57, 1707-1722, 2003.

[21]. J. A., Billings, J. D. Stoeckle. The Clinical Encounter: A Guide to the Medical Interview and Case Presentation (Second Edition), Mosby Year Book, St. Louis, MO, 1998.

[22]. J. D. Robinson. An interactional structure of medical activities during acute visits and its implications for patient participation, Health Communication, 15(1), 27-59, 2003.

[23]. W. B. Stiles. Stability of the verbal exchange structure of medical consultations, Psychology and Health, 11, 773-786, 1996.

[24]. J. Bruner. Acts of Meaning, Harvard University Press, Cambridge, 1990.

[25]. L. N. Rice, L. S. Greenberg. (Eds.). Patterns of Change, Guilford Press, New York, 1984.

[26]. J. D. Safran, L. S. Greenberg, L. N. Rice. Integrating psychotherapy research and practice: Modeling the change process, Psychotherapy, 25, 1-17, 1988.

[27]. E. G. Guba, Y. S. Lincoln. Fourth Generation Evaluation, Sage, Newbury Park, CA, 1989.
[28]. M. J. Packer, R. B. Addison. Evaluating an interpretive account. In M. J. Packer \& R. B. Addison (Eds.), Entering the Circle: Hermeneutic Investigation in Psychology, State University of New York Press, Albany, NY, 275-292, 1989.

[29]. T. Thompson. Introduction: Special issue: Coding provider-patient interaction, Health Communication, 13(1), $1-4,2001$.

[30]. W. B. Stiles. Levels of intended meaning of utterances, British Journal of Clinical Psychology, 25, 213 222, 1986.

[31]. H. B. Beckman, R. M. Frankel. The effect of doctor behavior on the collection of data, Annals of Internal Medicine, 101, 692-696, 1984.

[32]. M. R. Haug, B. Lavin. Consumerism in Medicine: Challenging Physician Authority, Sage, Beverly Hills, CA, 1983.

[33]. R. L. Street, W. R. Gold, T. McDowell. Discussing health-related quality of life in prenatal consultations. In G. H. Morris \& R. J. Chenail (Eds.), The Talk of the Clinic: Explorations in the Analysis of Medical and Therapeutic Discourse, Erlbaum, Hillsdale, NJ, 291-313, 1995.

[34]. H. Waitzkin. The Politics of Medical Encounters, Yale University Press, New Haven, CT, 1991.

[35]. W. Levinson, D. L. Roter, J. P. Mullooly, V. T. Dull, R. M. Frankel. Physician-patient communication: The relationship with malpractice claims among primary care physicians and surgeons, Journal of the American Medical Association, 277, $553-559,1997$.

[36]. L. A. Anderson, B. M. DeVellis, R. F. DeVellis. Effects of modeling on patient communication, satisfaction, and knowledge, Medical Care, 25, 1044-1056, 1987. 